\title{
An Experimental Approach for Understanding V-I Characteristic of Electric Arc Furnace Load
}

\author{
Mustafa Seker ${ }^{1}$, Arif Memmedov ${ }^{2}$ \\ ${ }^{I}$ Department of Electrical and Electronics Engineering, Faculty of Engineering, \\ Cumhuriyet University. 58140, Sivas, Turkey \\ ${ }^{2}$ Department of Electrical and Electronics Engineering, Faculty of Engineering, \\ Inonu University, 44280, Malatya, Turkey \\ mustafaseker@cumhuriyet.edu.tr
}

\begin{abstract}
Electric Arc Furnaces (EAF) are nonlinear loads causing power quality problems on the systems they are connected to. The main reason of EAFs causing power quality problems is the nonlinear characteristics of the electric arc. In this study, dynamic working characteristics of electric arc furnace load at Sivas Iron and Steel Incorporated Company (SIDEMIR) operating with 60 MVA EAF have been experimentally examined by HIOKI 3197 PQ analyser. Utilizing the measured dynamic load curves, mathematical equation and proper parameters have been determined for modelling electrical arc with the help of curve fitting methods on Matlab program. Also by modeling a phase equivalent of the system and harmonic filters existing on the system, a time domain model has been formed and with this model, harmonic effects of the EAF have been examined with Matlab/Simulink. Simulation results show that the presented model can be used for examining $P Q$ and voltage harmonics problems caused by EAF loads.
\end{abstract}

Index Terms-Electric arc furnace; V-I characteristics; curve fitting; harmonics.

\section{INTRODUCTION}

In recent years, the iron-steel industry has become a gradually expanding sector in most countries. Electric arc furnaces, with their high melting capacities and low production costs, are commonly used for melting metals in the iron-steel industry [1].

While having many economical advantages, EAFs also have many disadvantages because of PQ problems on the systems they are connected to. PQ problems such as harmonics, voltage unbalances, flicker can be noted as PQ problems caused by EAFs. PQ problems caused by EAF loads have been an important study subject for many researchers [2]-[6]. The main factor for EAFs causing power quality problems is the nonlinear characteristics and the time varying characteristics of the electric arc furnace loads [7]. To be able to define PQ problems caused by EAF loads the nonlinear stochastic structure of EAF loads and dynamic working characteristics should be understood well. It is hard to define the stochastic structure of EAF loads having rapid changes. For this reason, the main issue for examining PQ problems of EAFs is modelling the electrical

Manuscript received 14 November, 2016; accepted 18 March, 2017.

This work was supported by Inonu University Scientific Research Projects Department (IÜBAP). Project number: FDK-2011-135. arc. There are many methods used for modelling the electrical arc. While some researchers used differential equations based on time domain methods to define the stochastic structure of the EAF [8]-[11], some of them utilized nonlinear differential equations [12]-[13]. In addition to these studies, many methods such as electrical arc current-voltage characteristic (V-I) [14]-[17], linearizing methods [18]-[20] and frequency response analysis have been introduced by researchers in order to define EAF load behaviour and the working characteristics of EAF load have been tried to be determined with mathematical statements.

In this study, PQ measurements at Sivas Iron and Steel Incorporated Company (SIDEMIR) operating with $60 \mathrm{MVA}$ EAF have been realized by HIOKI 3197 PQ analyser. In electrical measurements, transient states of current and voltage have been recorded with 12 cycles and $1024 \mathrm{~Hz}$ sampling frequency and using this data the characteristic changes of current and voltage of the electric arc have been defined. A mathematical characteristic equation has been defined by using the data related to the electrical arc current and voltage characteristic and curve fitting methods with the help of Matlab curve fitting toolbox. Also by using the presented model and a phase equivalent circuit model the harmonic distortions have been compared to experimental data and the performance of the model in defining harmonic effects has been evaluated.

\section{Single-Phase Equivalent Circuit of the System FEEDING THE ARC FURNACE}

The single-line diagram of the electrical system feeding the 60 MVA EAF in Sivas Iron and Steel plant is shown in Fig. 1.

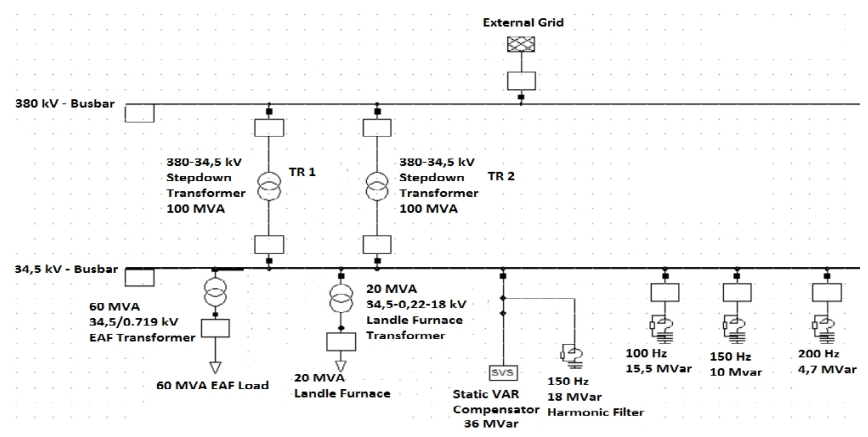

Fig. 1. The single-line diagram of the electrical system feeding the 60 MVA EAF. 
Given its single-line diagram, the electrical system's single-phase equivalent circuit model has been calculated with calculation acceptations stated in [21]-[24] and with the help of the parameters shown in Table I. According to the calculation results, for 719 Volt reference voltage the electrical system's single-phase equivalent circuit model $100 \mathrm{~Hz} 15.5$ MVar C type, $150 \mathrm{~Hz} 10$ MVar C type and $200 \mathrm{~Hz}$ 4.7 MVar with single tuned harmonic filters are as shown in Fig. 2.

TABLE I. CIRCUIT PARAMETERS OF THE SYSTEM FEEDING EAF.
\begin{tabular}{|c|c|}
\hline Utility & $\begin{array}{c}\text { Short Circuit Power }=7250 \mathrm{MVA} \\
\text { Utility Voltage }=380 \mathrm{kV}\end{array}$ \\
\hline Step-Down & Transformer Voltage Level $=380 / 34.5 \mathrm{kV}$ \\
Transformer & $100 \mathrm{MVA}$ \\
& $\% \mathrm{U}_{\mathrm{k}}=15$ \\
\hline EAF & Transformer Voltage Level $=34.5 \mathrm{kV} / 0.719 \mathrm{kV}$ \\
Transformer & $60 \mathrm{MVA}$ \\
& $\% \mathrm{U}_{\mathrm{k}}=4.9$ \\
\hline
\end{tabular}

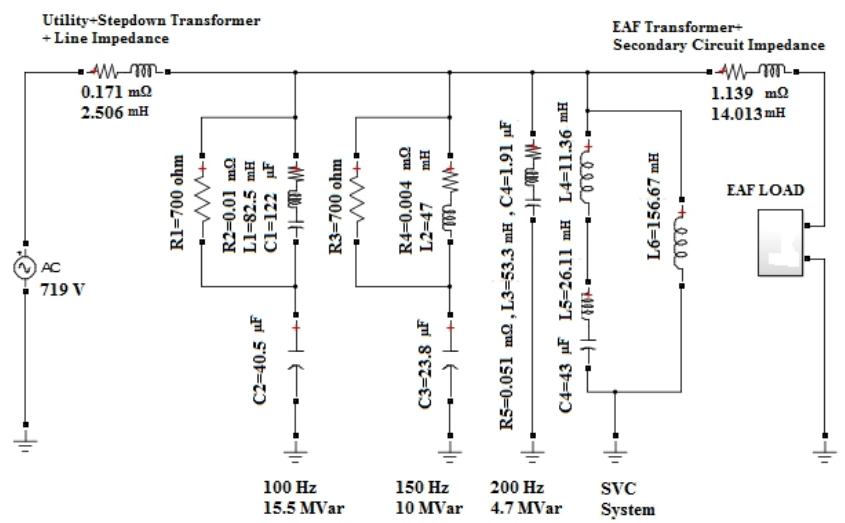

Fig. 2. Single-phase equivalent model for 719 Volt reference voltage of the system feeding the EAF.

\section{EXPERIMENTAL MEASUREMENT OF EAF-60 LOAD}

As shown in Fig. 1, HIOKI 3197 power quality analyser was connected to the secondary measurement cell of the Tr1 transformer as three phases and current and voltage changes at different operational processes of the EAF were recorded with 12 cycles and at $1024 \mathrm{~Hz}$ resolution according to the IEC 61000-4-30 standard [25].

\section{A. Experimental Measurement}

HIOKI 3197 power analyser was connected to the secondary busbar of the Tr-1 transformer and current and voltage fluctuations were recorded with 12 cycles and at $1024 \mathrm{~Hz}$ resolution according to four different operational status occurred at the melting process of the EAF as charging $(\mathrm{C})$, Boring (B), Melting (M) and refining(R) phases. Compensation and filter groups were not disabled during the measurements. Current and voltage values of each phase were calculated using the current parameters shown in Table I. In order to define EAF's dynamic characteristics, current and voltage fluctuations at the melting process were used. 12-cycle waveforms of current and voltage obtained by experimental measurements are respectively shown in Fig. 3 and Fig. 4. Also, active power change of the A phase of the EAF is shown in Fig. 5. Utilizing this power curve, Pmax is assumed about $14 \mathrm{MW}$.

Using the obtained experimental data's and single phase equivalent circuit parameters, the current and voltage values of the electrical arc were calculated for 719-volt reference voltage.

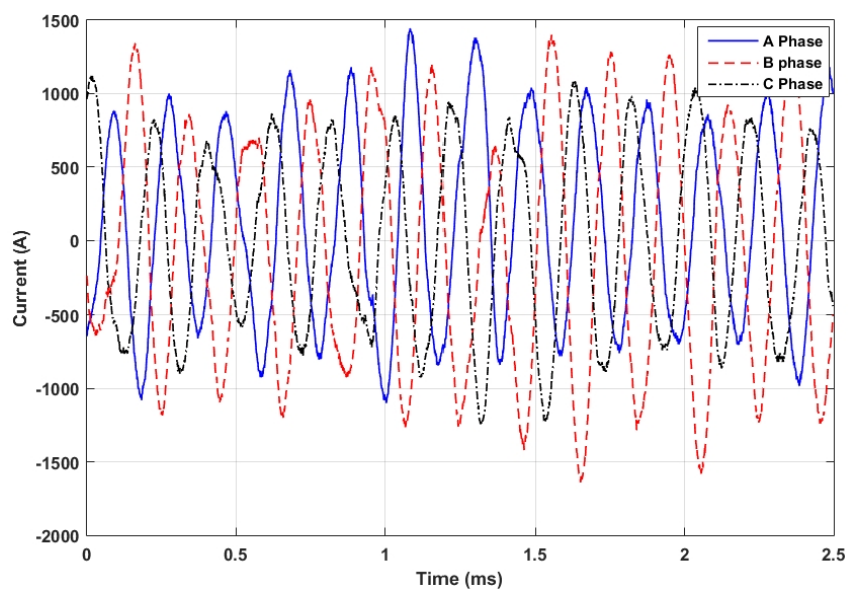

Fig. 3. Change of 12-cycle waveforms of three phase current obtained by experimental measurements at melting process.

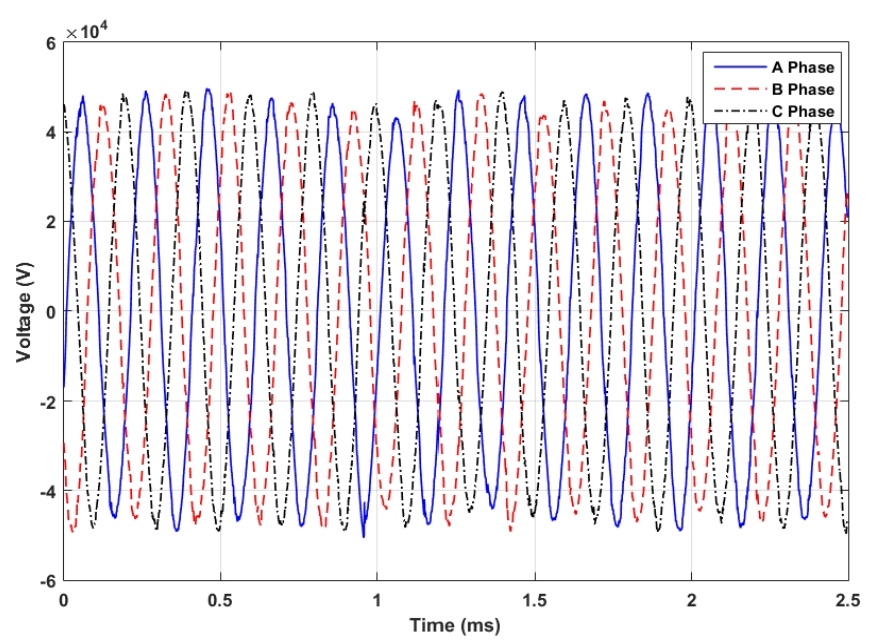

Fig. 4. Change of 12-cycle waveforms of three phase voltage obtained by experimental measurements at melting process.

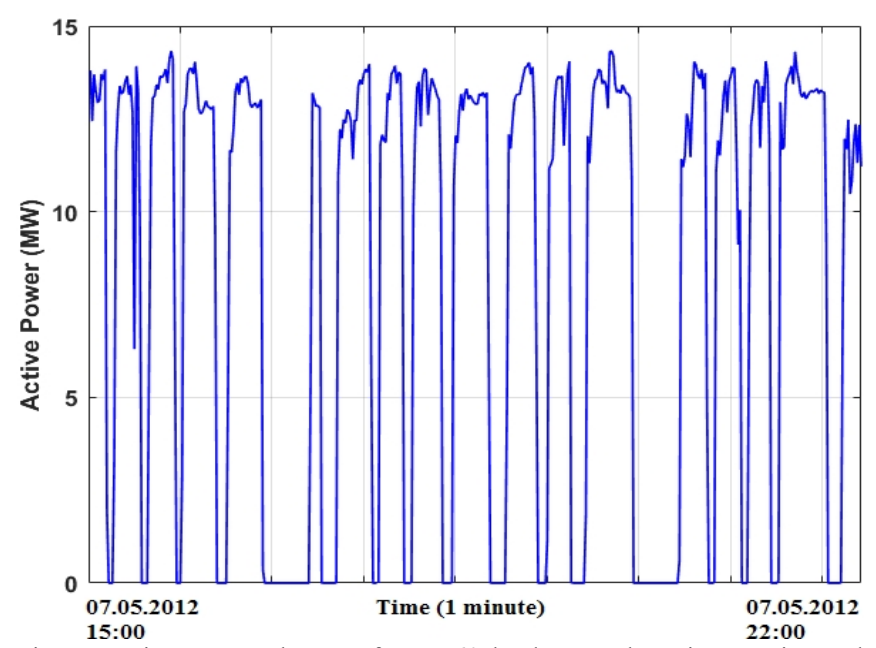

Fig. 5. Active power change of EAF-60 load to A phase in experimental measurements at melting process $\left(\mathrm{P}_{\max }=14.3 \mathrm{MW}\right.$, with one-minute average).

\section{Mathematical Modelling of the Electrical ARC USING CURVE FITTING METHOD}

Dynamic current voltage characteristic of the EAF in general statement can be expressed with the differential equation shown in (1) [26] 


$$
k_{1} \times r^{2}+k_{2} \times r \times \frac{d r}{d t}=\frac{k_{3}}{r^{2}} \times i^{2}=V_{a},
$$

where $r$ - arc angle, $i$ - instantaneous arc current, $k_{n}-\mathrm{a}$ proportional constant used for the model $(\mathrm{n}=1 \ldots 3), V_{a}$ arc voltage.

It is difficult to solve this differential equation and determine the coefficients. Therefore, to be able to model the current voltage characteristic, obtained by using the differential equation shown in (1), mathematically current and voltage can be separated to four basic characteristic areas shown in Table II.

TABLE II. DEFINITION OF THE CHARACTERISTIC AREAS FOR ELECTRICAL ARCCHARACTERISTIC.

\begin{tabular}{|c|c|}
\hline Area & Condition \\
\hline Area 1 & $(\mathrm{di} / \mathrm{dt})>0 \& \mathrm{i}>0 \& \mathrm{~V}_{\mathrm{a}}>0$ \\
\hline Area 2 & $(\mathrm{di} / \mathrm{dt})<0 \& \mathrm{i}>0 \& \mathrm{~V}_{\mathrm{a}}>0$ \\
\hline Area 3 & $(\mathrm{di} / \mathrm{dt})<0 \& \mathrm{i}<0 \& \mathrm{~V}_{\mathrm{a}}<0$ \\
\hline Area 4 & $(\mathrm{di} / \mathrm{dt})>0 \& \mathrm{i}<0 \& \mathrm{~V}_{\mathrm{a}}<0$ \\
\hline
\end{tabular}

The current voltage characteristic of the electric arc for EAF-60, measured of 12 periods real time, is shown in Fig. 6.

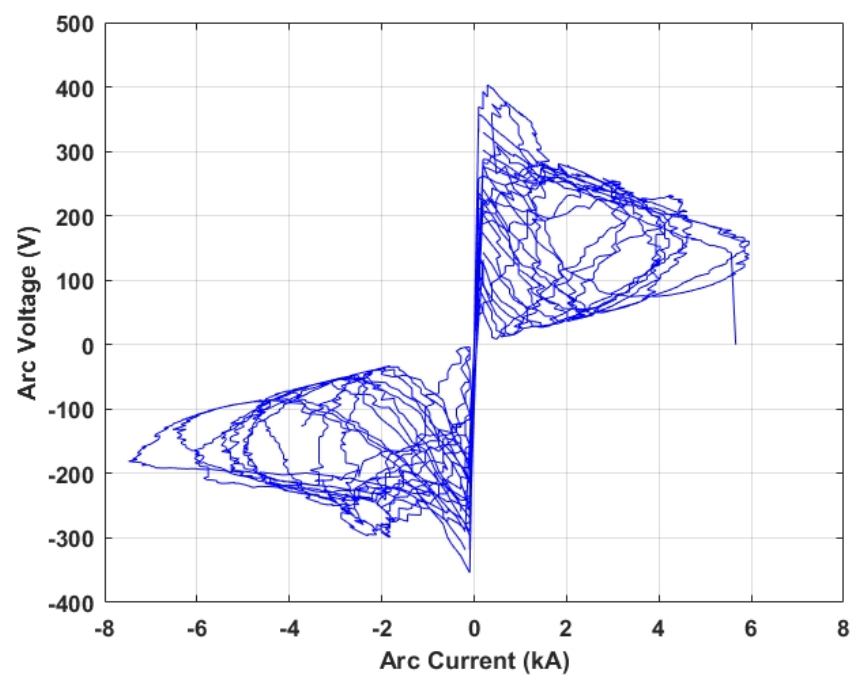

Fig. 6. Real time current voltage characteristic of the electric arc of the 60 MVA EAF measured by HIOKI 3197 power analyser.

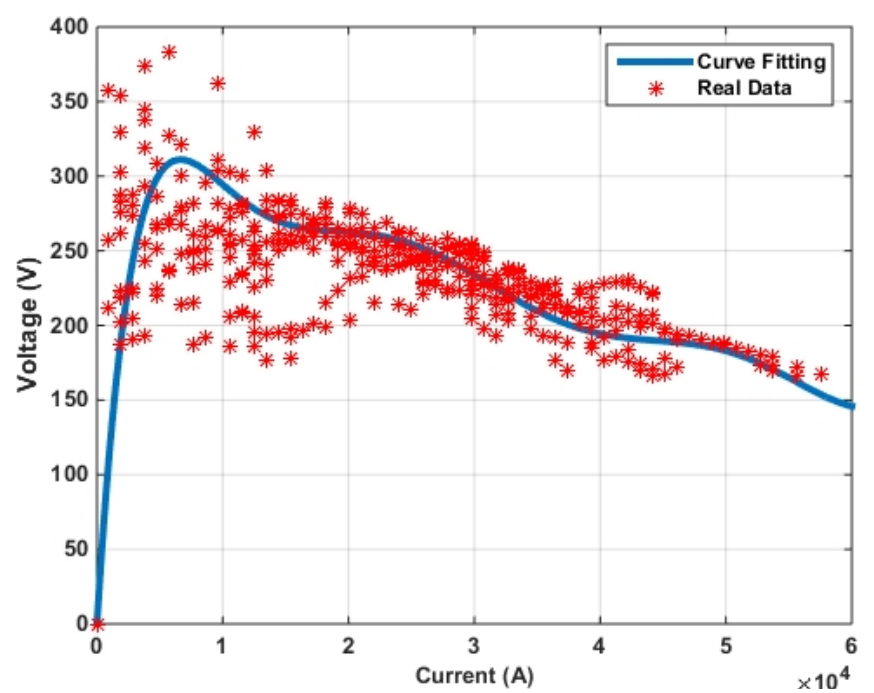

Fig. 7. The current and voltage measurement values meeting the $(\mathrm{di} / \mathrm{dt})>$ $0, \mathrm{i}>0$ and $\mathrm{V}_{\mathrm{a}}>0$ condition and the fitted polynomial curve of 9 th degree.

To be able to model the electric arc using this characteristic and Matlab Curve Fitting toolbox, the real measurement values obtained in Area 1 and Area 2 and fitted curves are graphically shown respectively in Fig. 7 and Fig. 8.

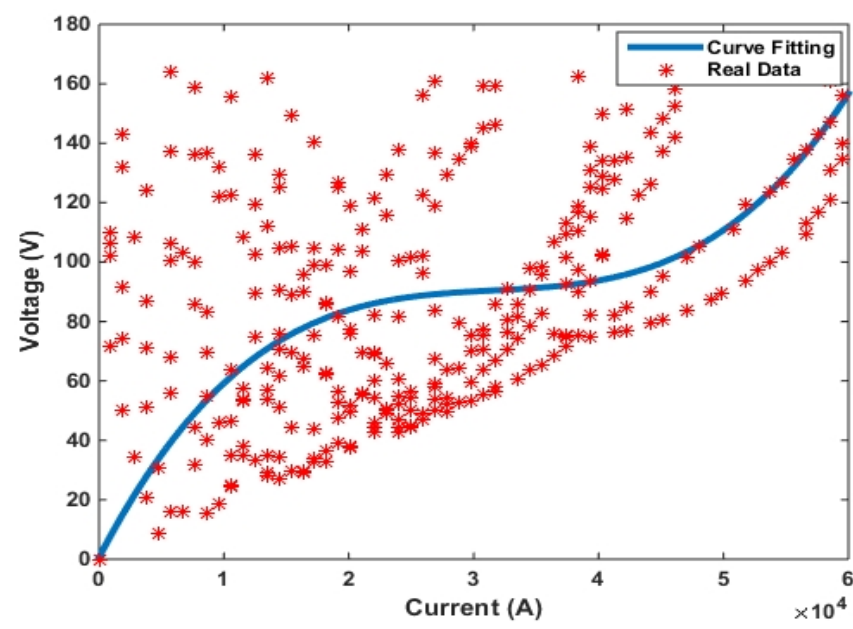

Fig. 8. The current and voltage measurement values meeting $(\mathrm{di} / \mathrm{dt})<0, \mathrm{i}>$ 0 and $\mathrm{V}_{\mathrm{a}}>0$ condition the fitted polynomial curve of 3 rd degree.

As shown in Fig. 7 and Fig. 8, the rise of the current can be modelled as a 9th degree polynomial equation and the drop can be modelled as a $3 \mathrm{rd}$ degree polynomial equation.

\section{Modelling OF THE ELECTRICAL ARC AND SimUlation RESULTS}

Single-phase equivalent circuit model of the system feeding the EAF shown in Fig. 2 has been modelled with Matlab/Simulink and the EAF load model, used for modelling of the electric arc, has been formed with the nonlinear impedance model shown in Fig. 9.

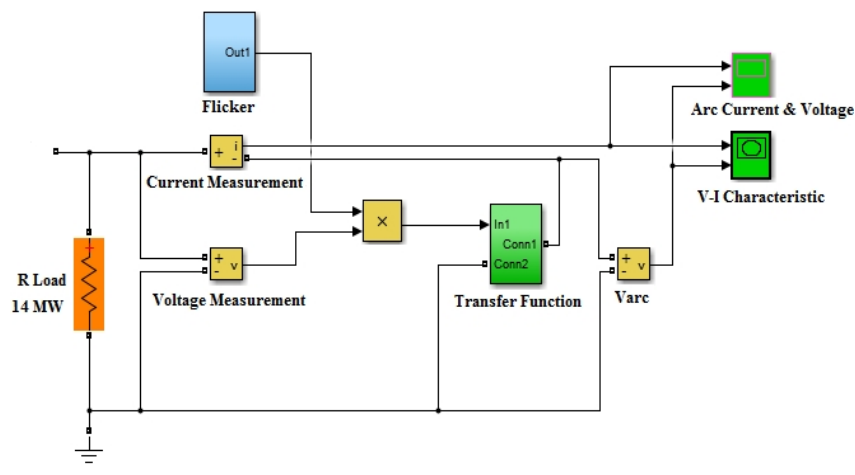

Fig. 9. The nonlinear impedance model, formed with Matlab/Simulink, of the EAF load used for modelling the electrical arc.

In this model, the $\mathrm{R}$ Load value has been measured as $14 \mathrm{MW}$ out of the power curves obtained by HIOKI 3197 power analyser according to Fig. 5. The transfer function has been formed using controlled current source (Fig. 10) and function block.

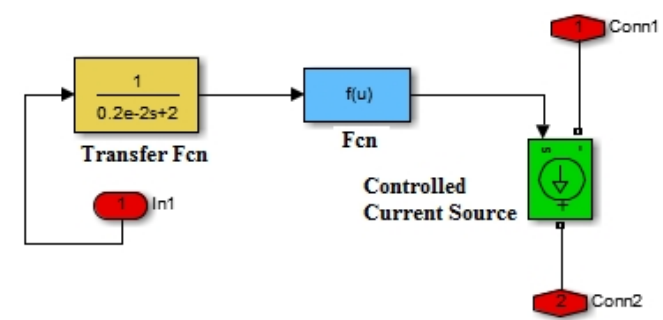

Fig. 10. The transfer function block defining the electrical arc. 
Here the mathematical expression of the Fcn function block is as in (2).

$$
i=I_{0} \times\left(\frac{V}{V_{a t}}\right)^{\alpha}
$$

In this expression, $V$ and $i$ are the instantaneous values of the current, $I_{0}$ is the reference current to determine the maximum voltage value and $V_{a t}$ is the threshold voltage. $\alpha$ is an exponential used to define nonlinear characteristic and it is used as $\alpha=15$ in this study. In the model, choosing $I_{0}=$ $60 \mathrm{kA}$ and $V_{a t}=120 \mathrm{~V}$ the simulation analysis has been realized and the dynamic V-I characteristic of the obtained electric arc has been shown in Fig. 11.

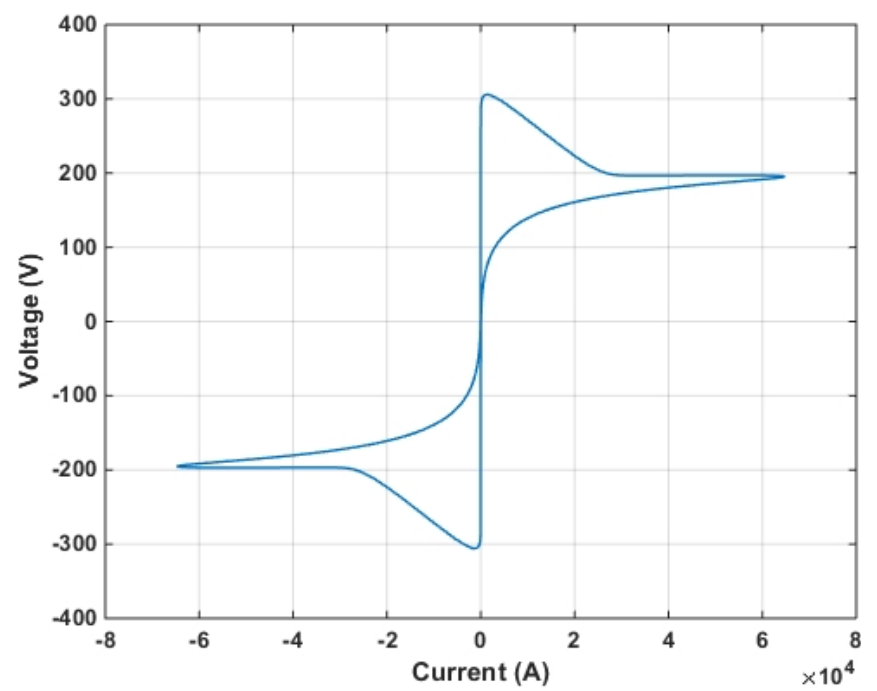

Fig. 11. The dynamic V-I characteristic curve of the electrical arc obtained by using simulation.

The $\frac{1}{0.2 e^{-2 s}+2}$ transfer function shown in Fig. 10 used to determine the value of the current obtained in the measurement results. Maximum arc current can be fixed with these transfer function and the current value can be adjusted for different furnace transformer tap with the aid of these transfer function.

This characteristic curve shows that 9th degree polynomial curve, obtained at current rise, can be modelled using proper parameters at the block structure shown in Fig. 6. Thus, the dynamic characteristic of the electrical arc can be defined. Accepting the drop of the current as an exponential function instead of 3rd degree function, the modelling of the electrical arc can be simplified. The dynamic current and voltage variation, obtained by the simulation, is graphically shown in Fig. 12.

In order to define the flicker effect caused by the electrical arc, the simulation results obtained by using the random flicker model presented in [16], [27] and the comparison of the data measured real timely are shown in Fig. 13, Fig. 14.

As shown in Fig. 13, when the dynamic characteristic of the electrical arc by flicker effect is observed it is seen that the drop curve of the current shows a change similar to 3rd degree polynomial statement. In Fig. 14 it is shown that, real-time measured arc voltage shows similarity with the arc voltage obtained by flicker effect by using simulation, and this model can be used to define the arc voltage.

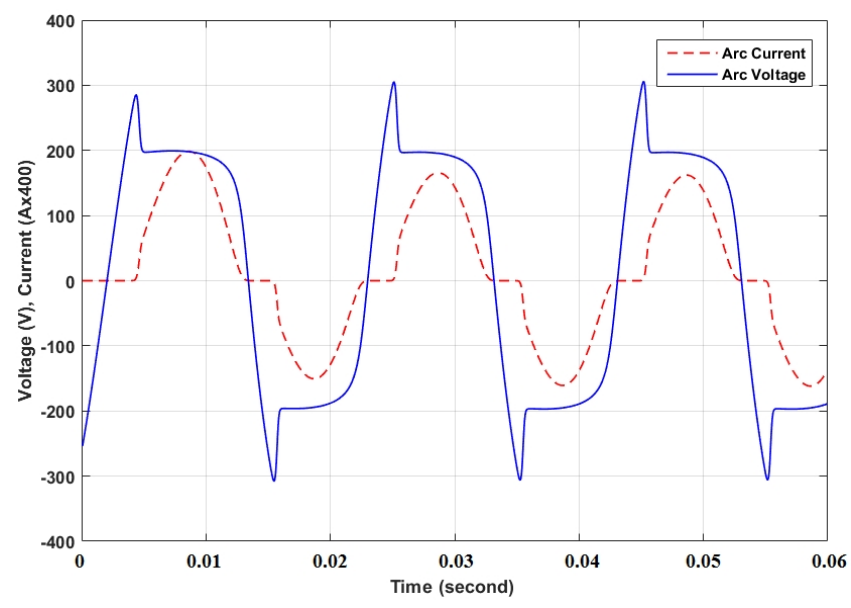

Fig. 12. The dynamic current and voltage variation obtained by the simulation (The current value has been downsized by ratio of $1 / 400$ to be able to show it scaled).

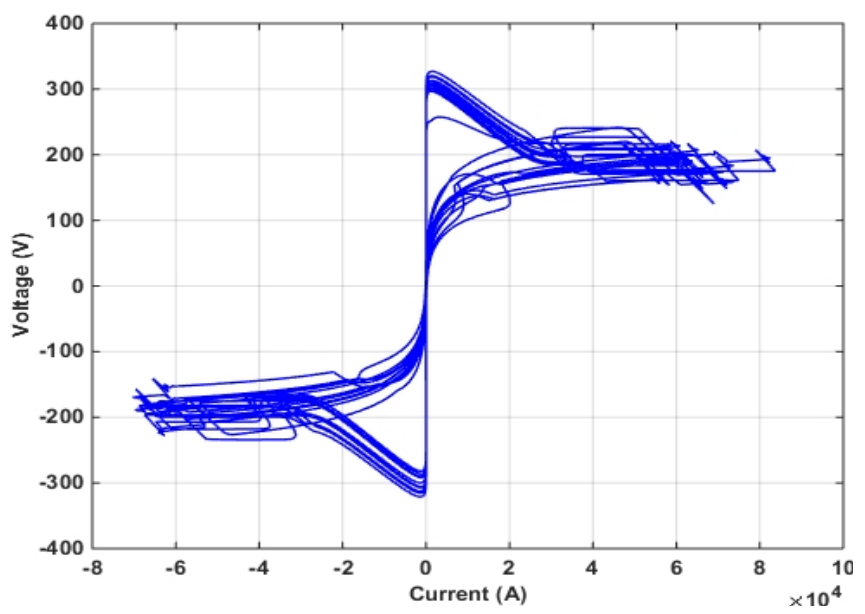

Fig. 13. The V-I characteristic curve of the electrical arc obtained by flicker effect as a result of the simulation.

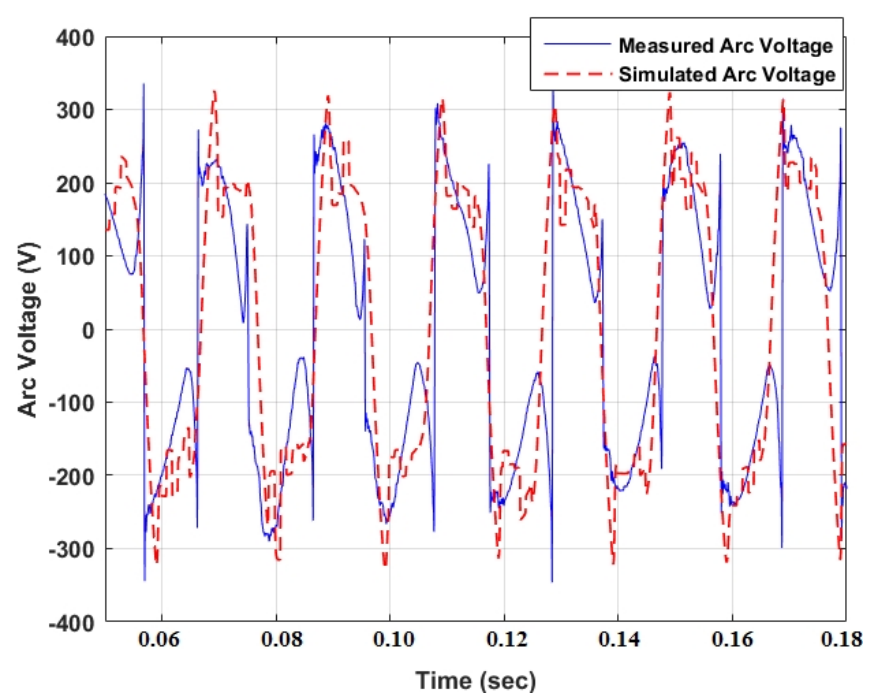

Fig. 14. Variation curves of the arc voltage obtained by Random flicker and the arc voltage measured.

The harmonic values on the transmission system caused by the arc characteristic of the simulation model and real timely measured harmonic voltage distortion values are shown in Table III. 
TABLE III. COMPARISON OF THE VOLTAGE HARMONIC VALUES MEASURED AT THE COMMON COUPLING POINT AND THE HARMONIC VALUES CALCULATED AS A RESULT OF THE SIMULATION.

\begin{tabular}{|c|c|c|c|c|c|c|}
\hline Measurement & $\begin{array}{c}2^{\text {rd }} \\
(\%)\end{array}$ & $\begin{array}{l}3^{\text {rd }} \\
(\%)\end{array}$ & $\begin{array}{l}4^{\text {rd }} \\
(\%)\end{array}$ & $\begin{array}{c}5^{\text {rd }} \\
(\%)\end{array}$ & $\begin{array}{l}7^{\text {rd }} \\
(\%)\end{array}$ & $\begin{array}{c}\text { THDV } \\
(\%)\end{array}$ \\
\hline A phase & 0.146 & 0.641 & 0.056 & 0.619 & 0.013 & 2.00 \\
\hline B Phase & 0.158 & 0.652 & 0.056 & 0.722 & 0.015 & 2.30 \\
\hline C Phase & 0.139 & 0.508 & 0,065 & 0.628 & 0.016 & 2.40 \\
\hline Simulation & $\begin{array}{l}2^{\text {rd }} \\
(\%)\end{array}$ & $\begin{array}{l}3^{\text {rd }} \\
(\%)\end{array}$ & $\begin{array}{l}4^{\text {rd }} \\
(\%)\end{array}$ & $\begin{array}{l}5^{\text {rd }} \\
(\%)\end{array}$ & $\begin{array}{l}7^{\text {rd }} \\
(\%)\end{array}$ & $\begin{array}{c}\text { THDV } \\
(\%)\end{array}$ \\
\hline $\begin{array}{l}\text { Simulation } \\
\text { Model }\end{array}$ & 0.100 & 0.650 & 0.040 & 0.550 & 0.240 & 2.15 \\
\hline
\end{tabular}

As shown in Table III, the applied simulation model also can be used for the determining of voltage harmonic distortion occurring on the electrical transmission system.

\section{CONCLUSIONS}

In this study, in order to define the dynamic V-I characteristic of the electrical arc, a simulation model has been developed by utilizing experimental studies and employing curve fitting methods with Matlab. In curve fitting, according to the electrical V-I characteristic, it is shown that the rise of the current can be defined as a 9th degree polynomial statement and the drop can be defined as a 3rd degree polynomial statement. But the random flicker effect used to define dynamic characteristical behavior of the electrical arc, is quite hard and complex to be applied with polynominal equations. So, using the parameters obtained from the fitted curves of the nonlinear impedance model is formed by Matlab Simulink. It has been shown that instead of solving polynomial equations, polynomial curves can be defined with the help of a transfer and an exponential functions defining the current voltage relation. Flicker effect can be easily used with the applied simulation model. This applied model can also be used for defining voltage harmonic effects and power quality problems of the EAF load. Also, arc models can be defined for arc furnaces of different voltage taps, the parallel load used in the designed nonlinear resistor model and changing the parameters of block used in the transfer function.

\section{APPENDIX A}

Polynomial coefficients for curve fitting:

Linear model Poly9:

$$
\begin{gathered}
f(x)=p 1 x^{9}+p 2 x^{8}+p 3 x^{7}+p 4 x^{6}+ \\
+p 5 x^{5}+p 6 x^{4}+p 7 x^{3}+p 8 x^{2}+p 9 x^{1}+p 10 .
\end{gathered}
$$

Coefficients (with $95 \%$ confidence bounds):

$p 1=2.878 \mathrm{e}-37, p 2=-7.783 \mathrm{e}-32, p 3=8.91 \mathrm{e}-27, p 4=$ $-5.624 \mathrm{e}-22, p 5=2.135 \mathrm{e}-17, p 6=-4.98 \mathrm{e}-13, p 7=6.995 \mathrm{e}-09$, $p 8=-5.521 \mathrm{e}-05, p 9=0.2098, p 10=0.1143$.

Goodness of fit:

SSE: $3.494 \mathrm{e}+05$;

R-square: 0.9809;

Adjusted R-square: 0.9808;

RMSE: 11.71.

Linear model Poly3:

$$
f(x)=p 1 x^{3}+p 2 x^{2}+p 3 x^{1}+p 4
$$

Coefficients (with $95 \%$ confidence bounds):

$p 1=2.631 \mathrm{e}-12, p 2=-2.495 \mathrm{e}-07, p 3=0.008101, p 4=$ 0.5906 .

Goodness of fit:

SSE: $4.495 \mathrm{e}+05$;

R-square: 0.8116 ;

Adjusted R-square: 0.8114;

RMSE: 13.27 .

\section{ACKNOWLEDGMENT}

The authors are indebted to reviewers for their constructive suggestions which significantly helped in improve the quality of this paper and SIDEMIR and TEIAS personnels.

\section{REFERENCES}

[1] O. Ozgun, A. Abur, "Flicker study using a novel arc furnace model", IEEE Trans. and Power Delivery, vol. 17, no. 4, pp. 1158-1163, 2002. [Online]. Available: http://dx.doi.org/10.1109/TPWRD. 2002.804013

[2] P. E. Issouribehere, F. Issouribehere, G. A. Berbera, "Power quality and operating characteristics of electric arc furnace", in Proc. IEEE Power Eng. Soc. Genarel Meeting, 2005, pp. 784-791. [Online]. Available: http://dx.doi.org/10.1109/PES.2005.1489388

[3] P. E. Issouribehere, J. C. Barbero, G. A. Berbera, F. Issouribehere, "Compatibility between disturbance emission and argentinian power quality regulations in iron and steel industry", in Proc. IEEE Transmission \& Distribution Conference and Exposition (TDC 2006), Latin America, pp. 1-6. [Online]. Available: http://dx.doi.org/ 10.1109/TDCLA.2006.311427

[4] J. G. Mayordomo, E. Prieto, A. Hernandez, L. F. Beites, "Arc furnace characterization from an off-line analysis of measurement", in Proc. IEEE 9th Int. Conf. Harmonics Quality Power, Orlando, FL, 2000, pp. 1073-1078. [Online]. Available: http://dx.doi.org/10.1109/ ICHQP.2000.896877

[5] S. I. Deacanu, N. Nopa, A. I. Toma, M. Topor, "Modelling and experimental analysis for modernization of 100 -t EAF", IEEE Trans. Industral Applications, vol. 46, no. 6, pp. 2259-2266, 2010. [Online]. Available: http://dx.doi.org/10.1109/TIA.2010.2072977

[6] M. P. Donsion, J. A. Guemes, F. Oliviera, "Influence od a SVC on $\mathrm{AC}$ arc furnaces harmonics, flicker and unbalance measurement and analysis", 15th IEEE Mediterranean Electrotechnical Conf. (MELECON), Valletta, Malta, 2010. [Online]. Available: http://dx.doi.org/10.1109/MELCON.2010.5476032

[7] M. A. P. Alonso, M. P. Donsion, "An improved time domain arc furnace model for harmonic analysis", IEEE Trans. Power Delivery, vol. 19, no. 1, pp. 367-373, 2004. [Online]. Available: http://dx.doi.org/10.1109/TPWRD.2003.820189

[8] R. C. Bellindo, C. Gomez, "Identification and modelling of athree phase arc furnace for voltage disturbance simulation", IEEE Trans. Power Deliver Delivery, vol. 12, no. 4, pp. 1812-1817, 1997. [Online]. Available: http://dx.doi.org/10.1109/61.634210

[9] H. Mokhtari, M. Hejri, "A new three phase time-domain model for electric arc furnace using Matlab", IEEE/PES Transmission and Disturbution Conf. and Exhibition, Yokohama, Japan, 2002, pp. 2078-2083. [Online]. Available: http://dx.doi.org/10.1109/TDC.2002. 1177781

[10] P. Chittora, A. Singh, M. Singh, "Modelling and analysis of power quality problems in electric arc furnace", Annual IEEE India Conf. (INDICON), 2015, pp. 1-6. [Online]. Available: http://dx.doi.org/ 10.1109/INDICON.2015.7443638

[11] S. Golestani, H. Samet, "Generalised Cassie-Mary electrical arc furnace models", IET Generation, Transmission \& Disturbution, vol. 10, no. 13, pp. 3364-3373, 2016. [Online]. Available: http://dx.doi.org/10.1049/iet-gtd.2016.0405

[12] H. Schau, D. Stade, "Mathematical modelling of three phase arc furnaces", in Proc. IEEE Int. Conf. Harmonics in Power Systems, 1994, pp. 422-428.

[13] H. M. Petersen, R. G. Koch, P. H. Swart, R. Heeerden, "Modelling arc furnace flicker investigation compensation techniques", Thirtieth 
IAS Annual Meeting Int. Conf. Industrial Application, (IAS! 1995), 1995, pp. 1733-1740. [Online]. Available: http://dx.doi.org/ 10.1109/IAS.1995.530515

[14] T. Zheng, E. B. Makram, A. Girgis, "Efect of different arc furnace model on voltage distortion", in IEEE Conf. Harmonics and Power Quality of Power, Athens, Greece, 1998, pp. 1079-1085. [Online]. Available: http://dx.doi.org/10.1109/ICHQP.1998.760189

[15] G. C. Montanari, M. Loggini, A. Cavallini, "Arc furnace model fort he study of flicker compensation in electrical network", IEEE Trans. Power Delivery, vol. 9, no. 4, 1994. [Online]. Available: http://dx.doi.org/10.1109/61.329535

[16] M. Seker, A. Memmedov, "Investigation of voltage quality in electric arc furnace with Matlab/Simulink", International Journal of Engineering and Technological Research (IJETR), vol. 2, no. 11, 2014.

[17] R. Hooshmand, M. Benejad, M. T. Esfahani, "A new time domain model for electric arc furnace", Journal of Electrical Engineering, vol. 59, no. 4, pp. 195-202, 2008.

[18] M. Anxo, P. Alonso, M. Perez, "An improved time domain arc furnace model for harmonic analysis", IEEE Trans. Power Delivery, vol. 19, no. 1, pp. 367-373, 2004. [Online]. Available: http://dx.doi.org/10.1109/TPWRD.2003.820189

[19] S. Varadan, E. B. Makram, A. Girgis, "A new time domain model voltage source for an arc furnace using EMTP”, IEEE Trans. Power
Delivery, vol. 11, no. 3, 1996. [Online]. Available: http://dx.doi.org/ 10.1109/61.517535

[20] T. Zheng, E. B. Makram, "An adaptive arc furnace model", IEEE Trans. Power Dlivery, vol. 15, no. 3, pp. 931-939, 2000. [Online]. Available: http://dx.doi.org/10.1109/61.871355

[21] J. R. Bello, "Fundamentals of the electric arc furnace", in Proc. Electric Furnace, vol. 29, 1971, p. 219.

[22] E. J. Borrebach, "Maximum power operation of electric arc furnaces", Iron and Steel Engineering, p. 74, 1969.

[23] D. L. Pelfrey, "Specifying arc furnace transformers", Electric Furnace Conf., Pittsburg, Pa, 1980.

[24] L. Di Stasi, Electric Furnaces. Padova, Italy: Patron ed., 1976. (in Italian).

[25] Testing and Measurement Techniques - Power Quality Measurement Methods, IEC 61000-4-30, 2003

[26] E. Acha, A. Semlyen, N. Rajakovic, "A harmonic domain computational package for nonlinear problems and its application to electric arcs", IEEE Trans. Power Delivery, vol. 5, pp. 1390-1397, 1990. [Online]. Available: https://doi.org/10.1109/61.57981

[27] M. Seker, A. Memmedov, R. Huseyinov, "The modelling of three phases electric arc furnace system using Matlab/SIMULINK and examining the harmonic effects with FFT analysis", Int. Artificial Intelligence and Data Processing Symposium (IDAP 2016), Malatya, Turkey, 2016. 